\title{
Recombinant Amphiregulin
}

National Cancer Institute

\section{Source}

National Cancer Institute. Recombinant Amphiregulin. NCI Thesaurus. Code C1000.

A recombinant form of amphiregulin, a member of the heparin-binding epidermal growth factor (EGF) family. Endogenous amphiregulin is an autocrine growth factor, and binds to the EGF receptor. Overexpressed in several cancer cell types, endogenous amphiregulin may contribute to tumor cell proliferation and metastasis. ( $\mathrm{NClO4)}$ 